\title{
Short rib-polydactyly syndrome: a single or heterogeneous entity? A re-evaluation prompted by four new cases
}

\author{
RENÉE BERNSTEIN, JOY ISDALE*, MAXIMINA PINTO, \\ J DU TOIT ZAAIJMAN, ANDT JENKINS \\ From the Department of Human Genetics, School of Pathology, The South African Institute for Medical \\ Research and University of the Witwatersrand; and *Department of Radiology, University of the \\ Witwatersrand, Johannesburg, South Africa.
}

SUMMARY Four cases of lethal short rib-polydactyly syndrome (SRPS) from three nonconsanguineous families are described. Radiological features were similar in all four cases and were most consistent with type III SRPS (Verma-Naumoff syndrome), but many differences in external and systemic abnormalities were noted. The considerable overlap of supposedly distinctive features displayed by the three main forms of SRPS is suggestive of a single locus mutation with variable expressivity, particularly for types I and III, possibly related to different mutant alleles and secondary intrauterine modification of the phenotype. All four cases showed anomalous sexual development. In spite of testicular differentiation in all four and a $46, \mathrm{XY}$ karyotype in the two on whom chromosome studies were done, two infants were phenotypic females and two had ambiguous genitalia. A definitive diagnosis of SRPS was made at 26 weeks' gestation in a pregnancy at risk.

The extreme, lethal forms of dwarfism have presented difficulties in their delineation and classification because of their relative rarity and shared dysmorphic features. In 1971, Majewski et al ${ }^{1}$ reported a characteristic form of lethal osteochondrodysplasia, the short rib-polydactyly syndrome (SRPS), and the following year Saldino and Noonan ${ }^{2}$ documented another form of SRPS. In 1977, Naumoff $e t a l^{3}$ described yet another variant (type III), which the authors considered to be distinctive from the Saldino-Noonan syndrome (type I) and the Majewski syndrome (type II), but closely resembling the type described in 1975 by Verma et al. ${ }^{4}$

The revised International nomenclature of constitutional diseases of bone in $1978^{8}$ clarified some of the pre-existing confusion in the classification of the osteochondrodysplasias, but as more cases of SRPS were described it became apparent that there was considerable overlap in the features displayed by the three forms of SRPS, particularly between types I and III. ${ }^{6}$ To add to the confusion in nosology and terminology, Cherstvoy et $\mathbf{l}^{7}$ referred to Majewski SRPS as type I and Saldino-Noonan SRPS as type

Received for publication 6 March 1984. Accepted for publication 18 May 1984.
II, and proposed a type IV SRPS for the case described by Piepkorn et al. ${ }^{8}$ Other variant forms of SRPS have also been reported. ${ }^{910}$

Several reports of parental consanguinity ${ }^{10-13}$ and more than one affected $\mathrm{sib}^{2-4} 10{ }^{13-17}$ support a recessively inherited autosomal single gene mutation. However, the debate as to whether the various forms of SRPS are the result of point mutations at different gene loci, differing mutations at the same locus, or variability in expression of the same mutant gene ${ }^{67}$ will not be satisfactorily resolved until the actual biochemical and molecular defects causing the severe multiple organ defects in early embryogenesis are identified.

The sexual ambiguity that frequently accompanies the generalised dysmorphogenesis of SRPS has $\tilde{\sim}$ resulted in a reported preponderance of females, $\underset{\omega}{\omega}$ particularly in the more severely affected cases. ${ }^{6}{ }^{18}$ 을

The present report documents four cases of SRPS (two of them sibs) which illustrate the considerable overlapping of morphological and radiological fea- $\stackrel{\mathscr{D}}{?}$ tures between the different types of SRPS and the $\square$ extreme degree of anomalous secondary sexual $O$ differentiation that can occur in this lethal form of $\stackrel{\mathbb{D}}{\circ}$ dwarfism. The antenatal diagnosis of this high $\stackrel{\mathbb{Q}}{\mathbb{Q}}$ recurrence risk syndrome is also discussed. 


\section{Case reports}

CASE 1

An abnormal stillborn female infant was delivered near term by Caesarian section. The 26 year old mother and 28 year old father were nonconsanguineous Afrikaners of Dutch descent. They had a normal 2 year old son and there was no history of previous miscarriages. The present pregnancy had been uneventful and, in particular, no oligo- or polyhydramnios had been noted.

The infant (fig 1) showed marked limb shortening, with a total length of $40 \mathrm{~cm}$ and a crown-rump length of $32 \mathrm{~cm}$, bilateral postaxial hexadactyly of fingers and toes, syndactyly of varying degree, and marked nail hypoplasia. A narrow and constricted thorax was evident and the abdomen was distended. The infant was severely hydropic, oedema being most conspicuous in the nuchal region and labial folds. There was no clitoral enlargement or anal atresia and gonads were not palpable in the labial folds or groin. The head appeared large (circumference $36 \mathrm{~cm}$ ) in relation to the rest of the body, the occiput and face were flattened, the ears were low set and deformed, the nasal bridge was broad and flat, and the facies resembled that found in Potter's syndrome. Indentation of the upper and lower lips was evident but they were not clefted.

At necropsy, a large persistent ductus arteriosus and a patent foramen ovale were found. The lungs were hypoplastic. The kidneys and ureters were absent and the bladder was small and contracted. The uterus and vagina were missing. Bilateral intra-abdominal gonads were shown to be composed entirely of immature fetal testicular tissue. The gastrointestinal tract was normal.
Histological sections of a long bone showed markedly irregular growth zones, with 'tongues' of cartilage extending into the metaphysis. Chondrocytes were plentiful, but were poorly organised and lacked columnisation.

Chromosome studies could not be performed because the infant had been placed in formalin.

A diagnosis of SRPS was made and the parents were given a $25 \%$ recurrence risk for future offspring.

\section{CASE 2}

The mother of case 1 conceived again 2 years later and careful clinical and sonar monitoring was instituted from the 13th week of gestation. In the 26th week sonar examination revealed severe oligohydramnios, fetal ascites, cephalic-body disproportion, and limb shortening. There was cardiac arrhythmia and only three fetal cardiac chambers could be visualised. After confirmation of sonar findings and $x$-ray examination at 28 weeks the parents elected to terminate the pregnancy. A short-limbed abnormal fetus, who survived for about 2 hours, was delivered by hysterotomy.

The appearance of the fetus (fig 2) was remarkably similar to the abnormal proband, but the syndactyly was more pronounced. The external genitalia were ambiguous: a small phallus and both gonads were palpable in the labioscrotal folds. Urethral and vaginal orifices were separate and the anus was patent.

At necropsy, a situs inversus with dextrocardia was noted; the left heart was hypoplastic with a vestigial left ventricle and mitral hypoplasia. The lungs were hypoplastic and the pancreas was dysplastic. Both kidneys were very small and dysplastic.
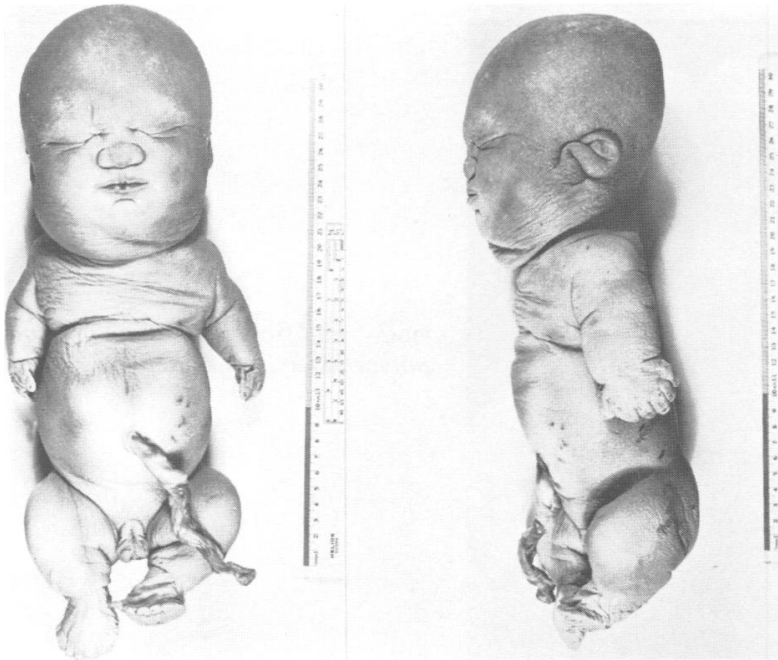

FIG 1 Full frontal view and side view of case 1. 


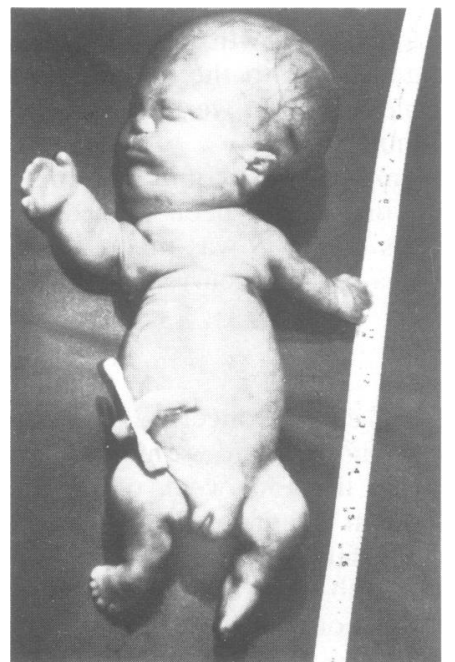

FIG 2 External appearance of case 2 (sib of case 1).

There was a rudimentary uterus and both gonads were composed of fetal testicular tissue. Bone formation and calcification were disorganised.

Chromosome studies on cultured skin fibroblasts revealed a normal male karyotype, 46,XY.

The parents of cases 1 and 2 have since had a normal child.

CASE 3

A stillborn, abnormal, phenotypically female infant (fig 3) was delivered at 37 weeks' gestation by Caesarian section, because of signs of 'placental insufficiency'. The 30 year old mother and 24 year old father were unrelated and of English ancestry. There was no relevant history in the father's family, but the mother had an epileptic brother who died during childhood and a niece who was born with an imperforate anus.

The couple's first pregnancy had ended in an early spontaneous miscarriage but the present pregnancy was entirely uncomplicated. Routine sonar scans at 16 and 22 weeks' gestation failed to reveal any fetal abnormality, but a third scan just before delivery indicated a 'small for dates' baby.

The marked limb reduction was associated with pre- and postaxial polysyndactyly of the left hand, which had seven digits, and postaxial hexadactyly of the right hand and both feet. Syndactyly was marked and the hands and feet resembled flippers (fig 3). The chest was narrow and constricted. The infant was not markedly hydropic, but redundant skin folds were present on the neck and trunk and the labial folds were swollen. The labiae contained no palpable gonads, the clitoris was normal, and there were separate urethral and vaginal orifices. The anus was imperforate. Head shape differed from cases 1 and 2 in that the occiput was rounded, the forehead was sloping with frontal bossing, the nose was saddle-shaped, and the ears were low set. The palate was normal, but natal teeth were noted in both upper and lower jaws.

At necropsy, the heart showed an endocardial cushion defect and a persistent ductus arteriosus. The lungs were hypoplastic. The gastrointestinal tract was normal apart from an imperforate anus. Both kidneys were small and dysplastic, with immature glomeruli and collecting tubules and undifferentiated mesenchyma. They contained small

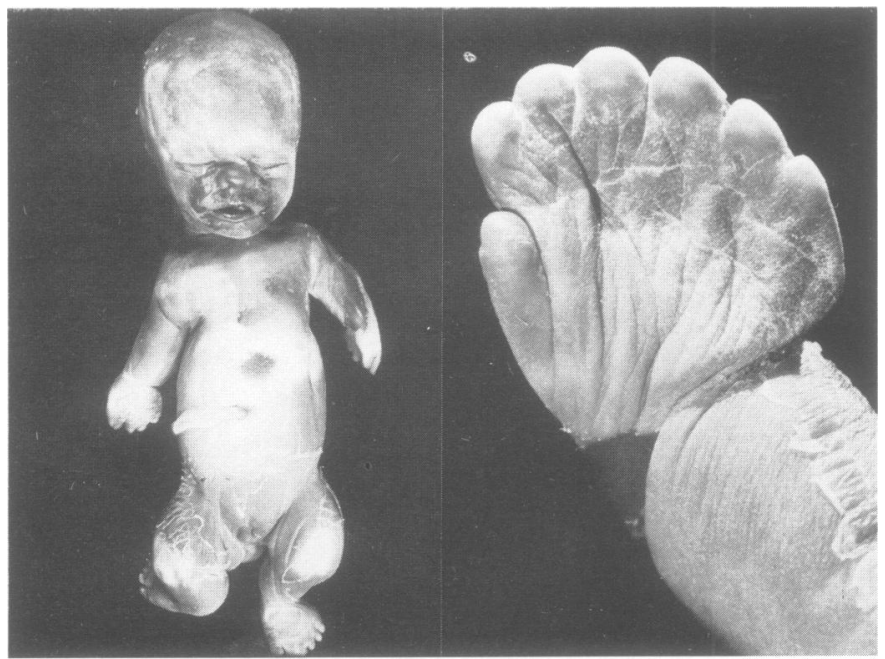

FIG 3 Full frontal view and pre-and postaxial polysyndactyly of the left hand of case 3 . 
islands of cartilage and calcification and cyst formation was observed. The ureters were hypoplastic but the bladder was normal. A rudimentary uterus and vagina were present. The left gonad was intraabdominal and the right was found at the entrance to the inguinal canal. Histological sections of both gonads showed only fetal testicular tissue, with recognisable epididymis and vas deferens.

Chromosome analysis of post mortem heart blood metaphases showed a normal male karyotype, $46, X Y$. The presence of a morphologically normal $\mathrm{Y}$ chromosome was confirmed by quinacrine fluorescence.

\section{CASE 4}

A 19 year old woman's uneventful first pregnancy ended at 32 weeks' gestation with the spontaneous delivery of an abnormal infant, who died a few minutes after birth. A sonar scan at 31 weeks' gestation revealed polyhydramnios but no fetal abnormality. The 30 year old father of the infant was unrelated to his wife and there was no relevant history of abnormality in either family, who were Afrikaans-speaking of Dutch descent.

The infant closely resembled case 3 with markedly shortened limbs associated with postaxial hexasyndactyly of both hands, but with only five partly fused toes on each foot. The chest was constricted and the abdomen distended. The external genitalia were ambiguous, with clitoral enlargement and very swollen labioscrotal folds containing small palpable gonads. There was no urethral or vaginal orifice and the anus was imperforate. The occiput was rounded, the forehead was bossed, the nose was saddleshaped, and the ears were low set. There was an equinovarus deformity of the left foot.

At necropsy, the lungs were hypoplastic but no cardiac abnormalities were detected. The gastrointestinal tract was normal apart from the imperforate anus. The kidneys were small and dysplastic. The cortex showed many tubules with early cystic dilation and small scattered areas of cartilage. The medulla showed abortive tubule formation, interspersed with primitive mesenchyma and smooth muscle fibres. The bladder and urethra were atretic. There was no uterus and both gonads, located in the upper regions of the labioscrotal folds, had the histological features of normal infantile testicular tissue.

Chromosome studies could not be performed because suitable specimens were not collected. Chromosome studies on both parents showed normal karyotypes.

$X$-RAY FINDINGS IN CASES 1 TO 4 (FIg 4 ) The skeletal abnormalities in the four fetuses were very similar. The salient radiological feature was the severely shortened tubular bones. Metaphyseal spurs were noted on the distal ends of the humerii, as well as on the proximal and distal ends of the radii and femora. The humerii had rounded medial ends, the ulnae were broad and amorphous, the tibiae

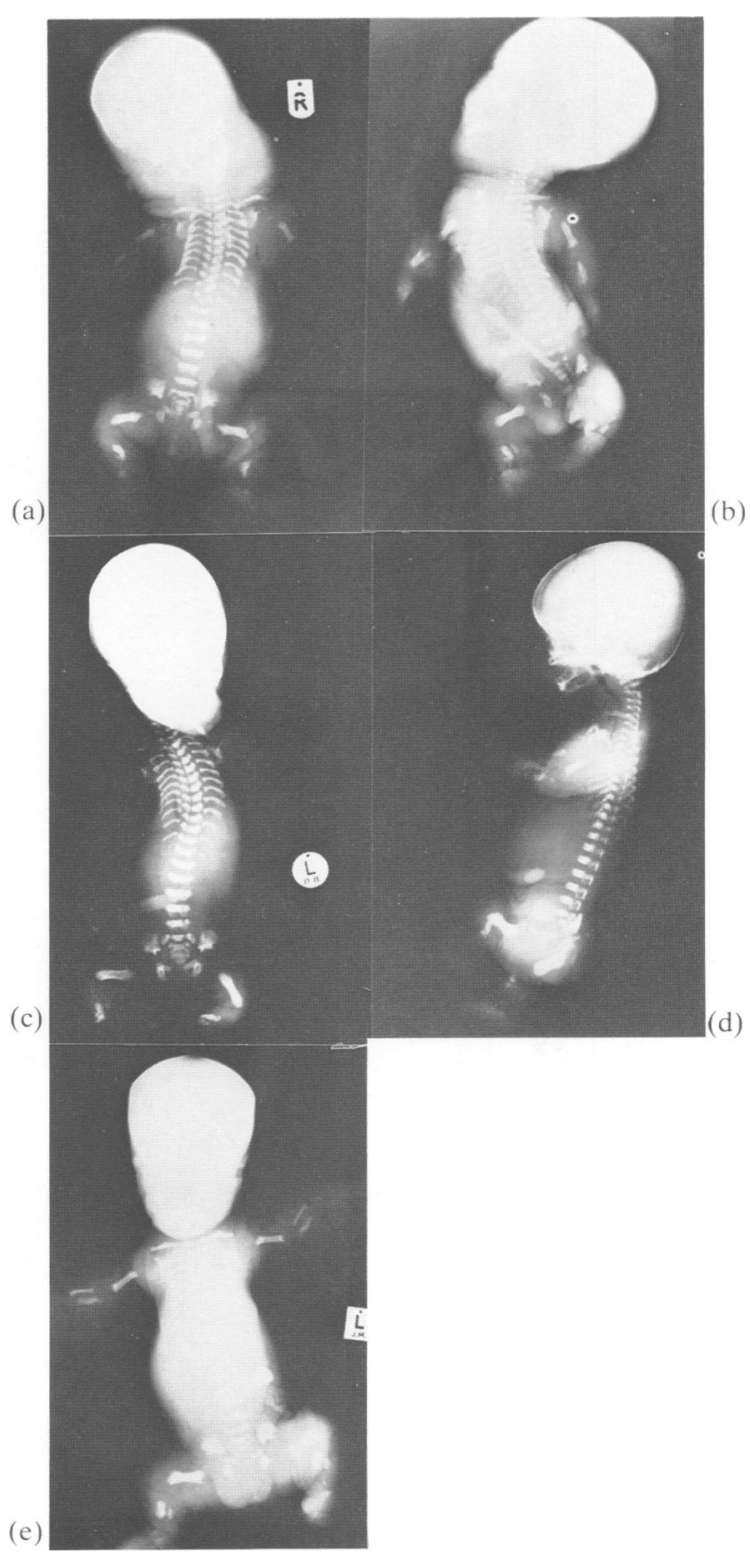

FIG 4 Radiological appearance of four cases of SRPS. (a) Anteroposterior view of case $1 ;(b)$ posterolateral view of case 2; (c) anteroposterior view of case 3; (d) lateral view of case 3; (e) anteroposterior view of case 4. 
were broad with a slight constriction at the junction of the lower and middle thirds, and the fibulae were very short and ovoid. Mineralisation and corticomedullary differentiation in all the long bones was good.

There were abnormal hypoplastic carpals, metacarpals, tarsals, metatarsals, and phalanges. Ribs were short and horizontal and showed markedly bulbous, almost bifid, anterior ends. Case 3 had only 11 right ribs and case 4 had 11 pairs of ribs. The pelves had trident lower margins, flat acetabulae, and small sacrosciatic notches; ischiae were broad with lateral spurring. The vertebrae were hypoplastic but of normal configuration, and the intervertebral discs were larger than the actual vertebral bodies. Interpedicular distance in all the lumbar vertebrae decreased slightly caudally. The skull appeared normal and lateral views (available in cases 2 and 3) showed no cranial base shortening. The mandibles were hypoplastic, the clavicles were of normal length, and the scapulae were rounded and slightly hypoplastic, with spurring of the coronoid processes.

The minimal differences noted between the four fetuses related mainly to the degree of ossification.

\section{Discussion}

The diagnosis of SRPS in these four cases was fairly obvious. There was marked limb reduction, polysyndactyly, short horizontal ribs with narrow constricted thorax and hypoplastic lungs, generalised systemic abnormalities, and early lethality. Identifying the specific type of SRPS is, however, difficult because of considerable overlapping of supposedly characteristic features distinguishing the three main types.

The salient features of the different types of SRPS described in published reports are referenced and compared to the findings in our four cases in the table. ${ }^{1-27}$ The radiological findings in the four cases were very similar. Differences in the degree of ossification are possibly related to the differing gestational ages of the four fetuses. They all showed features most consistent with type III (VermaNaumoff) SRPS but, in the two fetuses on whom lateral views were available (cases 2 and 3 ), the diagnostic cranial base shortening found in type III SRPS $^{3}$ was not evident. (One of these cases was the sib of case 1 and it is therefore presumed that both sibs suffered from the same type of SRPS.) The abnormal pelvic and vertebral features present in all four cases distinguished them from type II (Majewski) SRPS. The variable skeletal features in cases classified as types I or III have been emphasised by Sillence. ${ }^{6}$
In contrast to the fairly uniform radiological appearance of all four cases, their external features differed and are indicated in the table.

Systemic abnormalities appear to be more severe in type I SRPS. ${ }^{6720}$ Case 1 showed an essentially normally formed heart with persistent ductus arteriosus and foramen ovale, whereas case 2 (the sib) had a dextrocardia and severely hypoplastic left ventricle. Only case 4 showed no obvious cardiovascular lesion. Gastrointestinal tract malformations are also most frequent in type I; only case 2 of our series showed pancreatic fibrosis. Anal atresia, present in cases 3 and 4 , is thought to occur almost exclusively in type $\mathrm{I}^{2}{ }^{7}$ Complete renal agenesis found in case 1 is more consistent with type $I .^{21}$

The discrepancies found between the present cases and those published previously lead us to agree with Sillence ${ }^{6}$ that SRPS is probably a single entity with varying expressivity, although the severity of expression could be the result of different alleles at a single locus, particularly in types I and III. The evidence for allelism is less convincing for type II. The increasing number of variant abnormalities now described in over 50 cases suggests that SRPS is a single syndrome with a wider spectrum of features than was initially believed. $6-102027$ Although the skeletal manifestations of SRPS are the most dramatic, the generalised abnormalities of all organ systems suggest a defect in the regulation of cellular differentiation during early embryogenesis. This basic genetic defect could also be modified by external intrauterine factors thus causing variable phenotypes, for example, the hydrops could well be secondary to the cardiovascular and other systemic abnormalities.

An intriguing aspect of the general dysmorphogenesis of SRPS is the frequency with which anomalous sexual differentiation occurs. Our review of 51 cases showed an equal sex ratio: 24 were phenotypic females and 24 were classified as males, nine of the latter cases having ambiguous external genitalia. The sex was not stated in three cases. A female preponderance was noted in type I SRPS but not in types II and III (table).

Yang et al ${ }^{18}$ suggested that the female preponderance observed in cases reviewed by them was the result of more severe expression in males, leading to early intrauterine death. Sillence, ${ }^{6}$ on the other hand, interpreted this altered sex ratio as possibly being the result of more severe expression in females, with resultant selection bias, in that more severely affected cases were classified as type I SRPS. ${ }^{6}$ He found no overall alteration in the sex ratio of combined types I and III, which our review of all three types of SRPS confirms (table).

Very few of the documented cases report both the 
gonadal histology and chromosomal sex, so that it is difficult to decide if the failure of sexual differentiation is primary or secondary, namely, before or after differentiation of the primitive gonad. ${ }^{28}$ Chromosome studies were performed in 10 cases, four of whom were phenotypic females with a 46,XX karyotype $^{81214}$ The gonadal histology is recorded in only one of these females, who showed greatly diminished germ cells in the bilaterally small ovaries. ${ }^{8}$ Two of the six phenotypic males with a 46,XY karyotype ${ }^{911} 141627$ had ambiguous genitalia. ${ }^{11} 14$

In the present report, two of the four infants were phenotypic females (cases 1 and 3 ) and two had ambiguous genitalia (cases 2 and 4 ), yet all had differentiated gonads showing only testicular tissue, and chromosome studies on two of them (cases 2 and 3 ) revealed a normal male karyotype. In cases 1 and 4 the presence of fetal testes had suppressed Mullerian duct development, as evidenced by the absence of uterus and vagina, but in cases 2 and 3 a rudimentary uterus was found.

We therefore postulate that the predominantly female phenotype in severely affected cases is the result of a failure of secondary sexual differentiation in genetic and gonadal males.

An altered sex ratio has also been observed in campomelic dysplasia ${ }^{29}$; 14 of 17 reviewed cases were phenotypically female, but in eight of these females the chromosomal sex was male. In the few adequately documented cases, female internal genitalia were found, associated with either poorly differentiated ovarian tissue (XY gonadal dysgenesis) or an embryonic testicular pattern.

Antenatal diagnosis of SRPS in obligatory carrier parents has been reported twice previously. Richardson et al ${ }^{15}$ made an unequivocal radiographic diagnosis of SRPS at 29 weeks' gestation, but at 19 weeks the fetal long bones and spine could not be radiographically visualised and ultrasound examinations at 20 and 23 weeks were not definitive because of the poor visualisation of the extremities owing to oligohydramnios. Beemer et $\boldsymbol{l}^{10}$ were able to establish a definitive real-time ultrasound diagnosis by serial measurements of femora, fibulae, and tibiae between 17 and 20 weeks' gestation.

An unequivocal diagnosis of SRPS in our case 2 was only possible by ultrasound scanning at 26 weeks' gestation; earlier ultrasound diagnosis was hampered by severe oligohydramnios. The mothers of cases 3 and 4 had both had routine ultrasound examinations, but these failed to reveal the SRPS. Case 3 had routine examinations at 16, 22, and 36 weeks and only the latter scan was considered abnormal and indicative of a 'small for dates' baby. Case 4 had a routine scan at 31 weeks which showed polyhydramnios, but the abnormal fetus was not diagnosed.

The failure to demonstrate an affected fetus in ouro case 2 and the case of Richardson et al ${ }^{15}$ before음 the third trimester in an at risk pregnancy, and the $\frac{\bar{p}}{\frac{}{\sigma}}$ complete failure of ultrasound diagnosis during $\stackrel{\mathbb{\triangle}}{\varnothing}$ routine scanning of unsuspected cases, suggests that other alternative means of earlier antenatal diagnosis should be attempted in pregnancies at risk. As? SRPS is an early lethal condition, much anxiety $\vec{\omega}$ could be alleviated if reliable second trimester $\rho$ diagnosis were available. Fetoscopy during the $\overline{3}$ second trimester may be able to detect the polydactyly but the miscarriage rate associated with this procedure is estimated to be almost $4 \%$ even in experienced hands. ${ }^{30}$ The approach adopted by $\vec{\sigma}$ Beemer $e t a l^{10}$ of serial sonography from 16 to 20 을 weeks is certainly more logical than isolated ex- $\rightarrow$ aminations sporadically performed during the ${ }_{\infty}^{7}$ second and third trimesters. Furthermore, sonolog-o ists experienced in fetal ultrasound diagnosis should be consulted in at risk pregnancies.

We gratefully acknowledge and thank the followingo্ for their assistance in the investigation of the four cases described: Dr M Patz, Dr I Hatchuel, Profes-o sor A Schmaman (case 1), Dr M J Damant, Dr A ES Retief, Dr K van Heerden, Dr M J Greeff, Dr M Dō de Saxe, Professor P Beighton (case 2), Dr D足 Shulman, Dr C Wallace, Dr H v R Bruinette (caseฉ 3), Dr W A Swanepoel, and Dr D Tininin (case 4). $\overrightarrow{\overrightarrow{0}}$

\section{References}

1 Majewski F, Pfeiffer RA, Lenz W, Müller R, Feil G, Seiler R Polysyndaktylie, verkürzte gliedmassen und genitalfehlbildungen: Kennzeichen eines selbständigen syndroms? Z Kin derheilkd 1971;111:118-38.

2 Saldino RM, Noonan CD. Severe thoracic dystrophy with striking micromelia, abnormal osseous development, including the spine and multiple visceral anomalies. AJR 1972;114:3 257-63.

3 Naumoff P, Young LW, Mazer J, Amortegui AJ. Short음 rib-polydactyly syndrome type 3. Radiology 1977;122:443-7. I

4 Verma IC, Bhargava S, Agarwal S. An autosomal recessive form of lethal chondrodystrophy with severe thoracic narrowing, rhizo-acromelic type of micromelia, polydactyly and genitalN anomalies. Birth Defects 1975;11(6):167-74.

5 International nomenclature of constitutional diseases of bone. $\mathrm{NO}$ Pediatr 1978;93:614-6.

6 Sillence DO. Non-Majewski short rib-polydactyly syndrome. $\omega$ Am J Med Genet 1980;7:223-9.

7 Cherstvoy ED, Lurie IW, Shved IA, Lazjuk GI, Ostrowskaya TI, Usojev SS. Difficulties in classification of the short rib-polydactyly syndromes. Eur J Pediatr 1980;133:57-61. क

${ }^{8}$ Piepkorn M, Karp LE, Hickok D, Wiegenstein L, Hall JG. A lethal neonatal dwarfing condition with short ribs, polysyndactyly, cranial synostosis, cleft palate, cardiovascular and uro-우 genital anomalies and severe ossification defect. Teratology 1977;16:345-58.

9 Bidot-López P, Ablow RC, Ogden JA, Mahoney MJ. A case of short rib polydactyly. Pediatrics 1978;61:427-32. 
10 Beemer FA, Langer LO Jr, Klep-de Pater J, et al. A new short rib syndrome: report of two cases. Am J Med Genet 1983;14:115-23.

"Chen H, Yang SS, Gonzalez E, Fowler M, Al Saadi A. Short rib-polydactyly syndrome, Majewski type. Am J Med Genet 1980;7:215-22.

12 Black IL, Fitzsimmons J, Fitzsimmons E, Thomas AJ. Parental consanguinity and the Majewski syndrome. J Med Genet 1982;19:141-3.

${ }^{13}$ Cooper CP, Hall CM. Lethal short rib-polydactyly syndrome of the Majewski type: a report of three cases. Pediatr Radiol 1982;144:513-7.

${ }^{14}$ Spranger J, Grimm B, Weller M, et al. Short rib-polydactyly (SRP) syndromes, types Majewski and Saldino-Noonan. Z Kinderheilkd 1974;116:73-94.

15 Richardson MM, Beaudet AL, Wagner ML, Malini S, Rosenberg HS, Lucci JA. Prenatal diagnosis of recurrence of Saldino-Noonan dwarfism. J Pediatr 1977;91:467-71.

16 Motegi T, Kusunoki M, Nishi T, et al. Short rib-polydactyly syndrome, Majewski type, in two male siblings. Hum Genet 1979;49:269-75.

17 Rupprecht E, Gurski A. Kurzrippen-polydaktylie-syndrom typ Saldino-Noonan bei zwei geschwistern. Helv Paediatr Acta 1982;37:161-9.

18 Yang SS, Ching-Shen L, Al Saadi A, Bhim Sen Nangia, Bernstein J. Short rib-polydactyly syndrome, type 3 with chondrocytic inclusions: report of a case and review of the literature. Am J Med Genet 1980;7:205-13.

19 von Habeck J-O, Künzel W, Müller D, Tode G, Schmidt J. Kurzrippen-polydaktylie-syndrom typ III (Verma-Naumoff) mit zeichen einer ektodermalen dysplasie. Zentralbl Gynaekol 1982;104:568-75.
20) Belloni C, Beluffi G. Short rib-polydactyly syndrome, type Verma-Naumoff. ROEFO 1981;134:431-5

21 Leroy J. Saldino-Noonan short rib-polydactyly dwarfism syndrome. Clin Genet 1978:13:127.

22 Krepler R, Weissenbacher G, Leodolter S, Müller-Tyl E. Nicht lebensfähiger, mikromeler Zwergwuchs-ThoraxdystrophiePolydaktylie-syndrom typ Saldino-Noonan. Monatsschr Kinderheilkd 1976;124:167-73.

${ }^{23}$ Kataria S, Kushnick T. Short rib-polydactyly dwarfism: SaldinoNoonan type. Am J Dis Child 1982;136:640-1.

24 Lowry RB, Wignall N. Saldino-Noonan short rib-polydactyly dwarfism syndrome. Pediatrics 1975;56:121-3.

25 Kaibara N. Eguchi M, Shibata K, Takagishi K. Short ribpolydactyly syndrome type I Saldino-Noonan. Eur J Pediatr 1980;133:63-5.

26 Sommer A, Mulne A, Cordero L. The Majewski syndrome-a case report. Birth Defects 1977;13(3B):257-8.

27 Walley VM, Coates CF, Gilbert JJ, Valentine GH, Davies EM. Brief clinical report: short rib-polydactyly syndrome, Majewski type. Am J Med Genet 1983;14:445-52.

${ }^{28}$ Bernstein $\mathrm{R}$. The $\mathrm{Y}$ chromosome and primary sexual differentiation. JAMA 1981;245:1953-6.

29 Hall BD, Spranger JW. Campomelic dysplasia: further elucidation of a distinct entity. Am J Dis Child 1980;134:285-9.

30 Rodeck $\mathrm{CH}$. Foetoscopy guided by real-time ultrasound for pure foetal blood samples, foetal skin samples and examination of the foetus in utero. Br J Obstet Gynaecol 1980;87:449-56.

Correspondence and requests for reprints to $\mathrm{Dr}$ Renée Bernstein, Department of Human Genetics, The South African Institute for Medical Research, PO Box 1038, Johannesburg 2000, South Africa. 